\title{
Cancers in Patients with von Willebrand Disease: A Survey from the Italian Association of Haemophilia Centres
}

\author{
Massimo Franchini, MD ${ }^{1}$ Caterina Di Perna, MD ${ }^{2}$ Cristina Santoro, MD 3 Giancarlo Castaman, MD ${ }^{4,5}$ \\ Simona Maria Siboni, MD ${ }^{6}$ Ezio Zanon, MD ${ }^{7}$ Silvia Linari, MD ${ }^{5}$ Paolo Gresele, MD ${ }^{8}$ \\ Samantha Pasca, MD ${ }^{9}$ Antonio Coppola, MD ${ }^{10}$ Rita Santoro, MD, ${ }^{11}$ Mariasanta Napolitano, MD ${ }^{12}$ \\ Paola Ranalli, MD ${ }^{13}$ Annarita Tagliaferri, MD² and; On Behalf of the Italian Association of Haemophilia Centres*
}

${ }^{1}$ Department of Haematology and Transfusion Medicine, Carlo Poma Hospital, Mantova, Italy

2 Regional Reference Centre for Inherited Bleeding Disorders, University Hospital of Parma, Parma, Italy

${ }^{3}$ Haemophilia Centre of La Sapienza University, Roma, Italy

${ }^{4}$ Haemophilia Centre of Vicenza, Vicenza, Italy

${ }^{5}$ Regional Reference Centre for Inherited Bleeding Disorders, University Hospital of Florence, Florence, Italy

${ }^{6}$ Angelo Bianchi Bonomi Haemophilia and Thrombosis Centre, Fondazione IRCCS Ca' Granda Ospedale Maggiore Policlinico and University of Milan, Milan, Italy

${ }^{7}$ Haemophilia Centre of Padova, Padova, Italy

${ }^{8}$ Haemophilia Centre of Perugia, Perugia, Italy

${ }^{9}$ Haemophilia Centre of Udine, Udine, Italy

10 Haemophilia Centre of Naples, Naples, Italy

${ }^{11}$ Haemophilia Centre of Catanzaro, Catanzaro, Italy

12 Haemophilia Centre of Palermo, Palermo, Italy

13 Haemophilia Centre of Pescara, Pescara, Italy
Address for correspondence Massimo Franchini, MD, Department of Haematology and Transfusion Medicine, Carlo Poma Hospital,

Mantova, Italy (e-mail: massimo.franchini@aopoma.it).

\begin{abstract}
The complete list of coauthors for the study (Italian Association of Haemophilia Centres, with the site of the Haemophilia Centre given in parentheses, is as follows.

Cosimo Ettorre and Renato Marino (Bari); Piergiorgio Iannaccaro (Catanzaro); Flora Peyvandi (Milano); Giovanni Di Minno (Napoli); Gianna Franca Rivolta and Gabriele Quintavalle (Parma); Alfredo Dragani (Pescara); Silvia Macchi (Ravenna); Gianluca Sottilotta (Reggio Calabria); Attilia Maria Pizzini (Reggio Emilia); Maria Gabriella Mazzucconi (Roma); Piercarla Schinco (Torino); Anna Chiara Giuffrida (Verona).
\end{abstract}

Semin Thromb Hemost

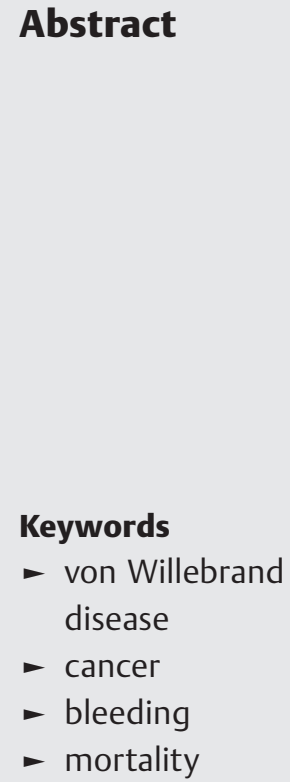

Besides its essential role in hemostasis, there is growing evidence that von Willebrand factor (VWF) has an additional antitumor effect. To elucidate the clinical significance of this biological activity we conducted a retrospective study on cancers among Italian patients with von Willebrand disease (VWD) on behalf of the Italian Association of Haemophilia Centres (AICE). A questionnaire to collect demographic, clinical, and treatment data of VWD patients with cancer was sent to all the 54 Italian Haemophilia Treatment Centres (HTCs) members of AICE. Overall, 18 HTCs (33\%) provided information on 92 VWD patients (61 alive and 31 deceased) with 106 cancers collected during the period 1981 to 2014 . Of them, 19 (18\%) were hematological cancers and 87 (82\%) were solid cancers. A total of $61 \%$ of patients had type $1,36 \%$ type 2 ( $12 \%$ type $2 \mathrm{~A}, 14 \%$ type $2 \mathrm{~B}, 9 \%$ type $2 \mathrm{M}$, and $1 \%$ type $2 \mathrm{~N}$ ), and $3 \%$ type 3 VWD: this distribution was significantly different from that observed in the whole VWD population (79\% type 1 , $16 \%$ type 2 [ $8 \%$ type $2 \mathrm{~A}, 4 \%$ type $2 \mathrm{~B}, 2 \%$ type $2 \mathrm{M}, 2 \%$ type $2 \mathrm{~N}$ ], and $5 \%$ type 3 ; type 2 vs. non-type 2: $p<0.001)$. Overall, VWD patients with cancer underwent 52 invasive and 72 surgical procedures, were treated with VWF/factor VIII (FVIII) concentrates in 77 cases, with desmopressin (DDAVP) alone in 24 cases and with DDAVP and VWF/FVIII
Issue Theme Editorial Compilation I; Guest Editors: Emmanuel J. Favaloro, PhD, FFSc (RCPA), and Giuseppi Lippi, MD.
Copyright @ 2015 by Thieme Medical Publishers, Inc., 333 Seventh Avenue, New York, NY 10001, USA.

Tel: +1(212) 584-4662.
DOI http://dx.doi.org/ 10.1055/s-0035-1564844. ISSN 0094-6176. 
concentrates in 7 cases. Hemorrhagic complications were observed only rarely ( $2 \%$ of invasive procedures and radiotherapy and $6 \%$ of surgical interventions). The data collected by this survey document that a substantial number of cancers are recorded among VWD patients and that these patients are safely managed by HTC physicians through a multidisciplinary approach.

von Willebrand factor (VWF), a large multimeric plasma protein synthesized by endothelial cells and megakaryocytes, plays a key role in promoting platelet adhesion and aggregation and in protecting coagulation factor VIII (FVIII) from proteolytic degradation. ${ }^{1-3}$ Besides its essential role in hemostasis, there is an increasing evidence that VWF may have an additional antitumor effect, mainly through its antiangiogenic and proapoptotic properties. ${ }^{4}$ Indeed, while the antiangiogenic action is exerted mostly by a negative modulation of vascular endothelial growth factor receptor-2-dependent angiogenesis, ${ }^{5}$ some experimental in vitro and in vivo studies have demonstrated a critical role of VWF in reducing metastasis by inducing tumor cell death. ${ }^{6,7}$ With this background, it is not surprising that several clinical studies have analyzed the relationship between circulating or tissue VWF levels and malignancies, ${ }^{8-15}$ but the interpretation of their results is greatly hindered by the fact that VWF levels may be altered during inflammation. It is, therefore, often difficult to establish exactly whether raised VWF levels are causal or a consequence of the underlying cancer-associated inflammatory process. On the other hand, so far only few studies, published exclusively as case reports, ${ }^{16-18}$ have systematically analyzed the issue of cancer in patients with congenital von Willebrand disease (VWD). Thus, on behalf of the Italian Association of Haemophilia Centres (AICE), we have conducted a study on cancer among Italian VWD patients followed at the Haemophilia Treatment Centres (HTCs) with the aim of shedding light on this still unclear issue.

\section{Patients and Methods}

\section{Study Design}

This retrospective study was approved by the Institutional Review Boards of AICE and by local ethical committees of the hospitals of the participating HTCs and was proposed at the beginning of 2012 to all member HTCs. The primary objective of the study was to describe the cases of cancer (type of neoplasm, patients' outcome, and type of treatment used) in the Italian population of VWD patients. A secondary aim was to investigate the influence, if any, of this inherited hemorrhagic disorder on the management and outcome of malignancies. Another secondary objective of our study was to assess whether a correlation exists between the entity of the VWF defect and the dissemination of malignancy at presentation.

A questionnaire designed to collect information on demographic, clinical, and therapeutic data of VWD patients with cancer was sent to all Italian HTCs that are members of AICE. All cases of confirmed cancer in VWD patients, alive or deceased and followed by the HTCs participating in the survey, were included. No restriction of period of inclusion was required. For each case, the following information was recorded: demographic data (date of birth, age at death, and cause of death), type and severity of VWD, VWF ristocetin cofactor (VWF:RCo) levels, type of mutation (if known), presence of blood-borne viral infections and their complications (i.e., chronic hepatitis B, chronic hepatitis $\mathrm{C}$, liver cirrhosis, hepatocellular carcinoma, human immunodeficiency virus [HIV] and acquired immunodeficiency syndrome, response to antiviral treatment for hepatitis C virus [HCV] or HIV), concomitant diseases, and therapeutic data (type of VWF/FVIII concentrate, desmopressin [DDAVP, Kedrion Biopharma, Castelvecchio Pascoli, Italy] usage, treatment regimen, and mean annual consumption). In addition, information was also collected on the type and stage of cancer, the date of diagnosis, the date and type of metastases, data on malignancy management (invasive/surgical procedures, factordeficient replacement therapy and bleeding complications at presentation and during treatment, type of chemotherapy or radiotherapy), occurrence of thrombocytopenia (platelet count $<50 \times 10^{9} / \mathrm{L}$ ), response to treatment, cancer progression or recurrence, outcome (alive or deceased) and the period of follow-up. All patients had regular followup visits at the HTC. We also collected information on whether VWD had influenced the choice and availability of cancer treatment modalities, patients' participation in experimental protocols, and completion of therapy or whether a reduction of the doses of chemotherapy had been necessary.

\section{Statistical Analysis}

All patients enrolled in the study were included in the descriptive statistical analysis. Descriptive analyses of the data were performed using summary statistics for categorical and quantitative data. The null hypothesis of a uniform distribution of the frequencies between different groups was analyzed by means of a Pearson chi-square test. Additionally, multivariable logistic analysis was performed and results are presented as odds ratios (OR) and corresponding 95\% confidence intervals $(\mathrm{CI})$.

\section{Results}

Total 18 of the 54 (33\%) Italian HTCs that are members of AICE agreed to participate in the study and provided 
information on 92 VWD patients (61 alive and 31 deceased at the end of survey) who developed 106 cancers during the period from January 1981 to June 2014. This cohort corresponded to $6 \%(92 / 1,465)$ of the VWD population followed by the enrolled HTCs, which represented $63 \%(1,465 / 2,317)$ of the whole Italian population of people with VWD. - Table 1 summarizes the characteristics of the VWD patients with cancer (number of patients alive and deceased, median age at diagnosis of cancer and death, HCV and HIV status) enrolled during the study period (19812014). The median age of patients at cancer diagnosis was 58 years (range, $21-85$ years), while the median age at death was 68 years (range, 21-84 years). In the majority of cases $(24 / 31,77 \%)$ the cause of death was cancer progression. Other causes of death were bleeding and infectious complications, which accounted for $10 \%(3 / 31)$ and $13 \%(4 / 31)$ of deaths, respectively. A total of 56 patients (61\%) had type 1 , 33 (36\%) had type 2 (12\% type $2 \mathrm{~A}, 14 \%$ type $2 \mathrm{~B}, 9 \%$ type $2 \mathrm{M}$, and $1 \%$ type $2 \mathrm{~N}$ ), and $3(3 \%)$ had type $3 \mathrm{VWD}$. Among type 1 VWD patients, nine (16\%) had type Vicenza variant VWD. Interestingly, this distribution of VWD type in cancer patients was quite different from that observed in the whole VWD population followed at the 18 HTCs participating in the study (79\% type 1 [including also Vicenza variant], 16\% type 2 [ $8 \%$ type $2 \mathrm{~A}, 4 \%$ type $2 \mathrm{~B}, 2 \%$ type $2 \mathrm{M}, 2 \%$ type $2 \mathrm{~N}$ ], and $5 \%$ type 3 ; type 2 versus non-type 2 distribution between cancer group and whole VWD population: $p<0.001$; OR 2.91; 95\% CI: 1.79-4.64). Concomitant viral infections were observed in 15 (16\%) patients (13 HCV, 1 HIV, 1 HIV/ HCV). - Table 2 shows the number, types, and diffusion of cancers according to patients' VWD type and viral infection status. Solid cancers accounted for the great majority (82\%) of the cases, while the remaining cases $(18 \%)$ were hematological cancers. All six cases of hepatocellular carcinoma recorded during the study period occurred in HCV-infected VWD patients, as did 30\% (3/10) of the cases of non-Hodgkin lymphoma. Notably, the rate of HCV infections was higher in patients with the more severe forms of VWD (2/3 [67\%] in type 3 VWD vs. 12/89 [13\%] in non-type 3 VWD). No difference in the distribution of VWD type was observed between patients with solid tumors (61\% type 1,37\% type 2 [13\% type $2 \mathrm{~A}, 12 \%$ type $2 \mathrm{~B}, 9 \%$ type $2 \mathrm{M}, 3 \%$ type $2 \mathrm{~N}$ ] and $2 \%$ type 3 ) and hematological cancers (58\% type 1, 37\% type 2 [ $11 \%$ type $2 \mathrm{~A}, 21 \%$ type $2 \mathrm{~B}, 5 \%$ type $2 \mathrm{M}$ ] and $5 \%$ type 3 ). A total of 13 patients had more than one cancer (12 had two cancers and 1 had three cancers) with the following distribution of VWD type: 8 type $1(7 \%)$ and 5 type $2(5 \%)$ ( 3 type $2 \mathrm{~A}, 1$ type $2 \mathrm{~B}, 1$ type $2 \mathrm{~N}$ ). The patient suffering from three cancers had a type $2 \mathrm{~N}$ VWD. A total of 23 (25\%) of the 94 cancers evaluable had metastasized before being diagnosed ( 15 type 1 [16\%], 8 type 2 [8\%] [ 5 type $2 \mathrm{~A}, 2$ type $2 \mathrm{~B}, 1$ type $2 \mathrm{M}]$ ). No statistically significant difference was observed between median basal plasma VWF:RCo levels in cancer patients with and without metastasis at presentation (VWF:RCo levels: $20 \mathrm{IU} / \mathrm{dL}$ [range, 6-49 IU/dL] vs. $19 \mathrm{IU} / \mathrm{dL}$ [range 1-48 IU/dL]; $p=$ nonsignificant).

- Table 3 shows the treatment characteristics of the VWD patients with cancer enrolled in the study. Overall,
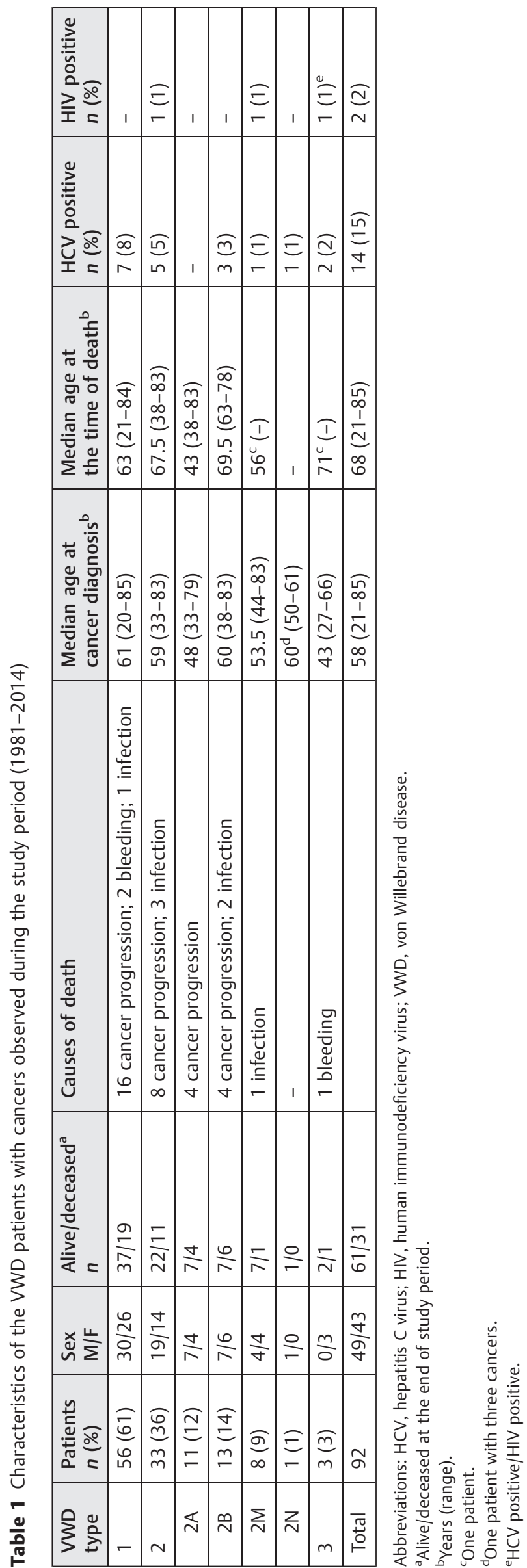
Cancers in Patients with von Willebrand Disease Franchini et al.

Table 2 Number, type, and diffusion of cancers according to the patients' VWD type and viral infection status

\begin{tabular}{|c|c|c|c|c|}
\hline Type of cancer & $\begin{array}{l}\text { Total } \\
n(\%)\end{array}$ & $\begin{array}{l}\text { VWD type } \\
n(\%)\end{array}$ & $\begin{array}{l}\text { Metastasis }^{\mathrm{a}} \\
n^{\mathrm{Q1}}(\%)\end{array}$ & $\begin{array}{l}\mathrm{HCV}+/ \mathrm{HIV}+ \\
n\end{array}$ \\
\hline Solid & $87(82)$ & $\begin{array}{l}53 \text { type } 1 ; 11 \text { type } 2 \mathrm{~A} ; 10 \text { type } 2 \mathrm{~B} \text {; } \\
8 \text { type } 2 \mathrm{M} ; 3 \text { type } 2 \mathrm{~N} ; 2 \text { type } 3\end{array}$ & 23 & $13 / 2$ \\
\hline Urogenital tract & $19(22)$ & $\begin{array}{l}9 \text { type } 1 ; 2 \text { type } 2 \mathrm{~A} ; 3 \text { type } 2 \mathrm{~B} ; 3 \\
\text { type } 2 \mathrm{M} ; 2 \text { type } 2 \mathrm{~N}\end{array}$ & 5 & $3 / 1$ \\
\hline Gastrointestinal tract & $17(19)$ & 14 type $1 ; 1$ type $2 \mathrm{~A} ; 2$ type $2 \mathrm{~B}$ & 4 & $2 / 0$ \\
\hline Breast cancer & $16(18)$ & $\begin{array}{l}8 \text { type } 1 ; 3 \text { type } 2 \mathrm{~A} ; 1 \text { type } 2 \mathrm{~B} ; 3 \\
\text { type } 2 \mathrm{M} ; 1 \text { type } 3\end{array}$ & 4 & $0 / 0$ \\
\hline Hepatocellular carcinoma & $6(7)$ & 4 type $1 ; 1$ type $2 \mathrm{~B} ; 1$ type $2 \mathrm{M}$ & 1 & $6 / 0$ \\
\hline Respiratory system & $9(10)$ & 5 type $1 ; 2$ type $2 \mathrm{~A} ; 2$ type $2 \mathrm{~B}$ & 5 & $0 / 0$ \\
\hline Pancreas & $3(3)$ & 3 type 1 & 1 & $0 / 0$ \\
\hline Other cancers $^{b}$ & $17(19)$ & $\begin{array}{l}11 \text { type } 1 ; 3 \text { type } 2 \mathrm{~A} ; 1 \text { type } 2 \mathrm{~B} ; 1 \\
\text { type } 2 \mathrm{M} ; 1 \text { type } 3\end{array}$ & 3 & $2 / 1^{c}$ \\
\hline Hematological & $19(18)$ & $\begin{array}{l}11 \text { type } 1 ; 2 \text { type } 2 \mathrm{~A} ; 4 \text { type } 2 \mathrm{~B} \text {; } \\
1 \text { type } 2 \mathrm{M} ; 1 \text { type } 3\end{array}$ & - & $4 / 0$ \\
\hline Non-Hodgkin lymphoma & $10(54)$ & 6 type $1 ; 1$ type $2 \mathrm{~A} ; 3$ type $2 \mathrm{~B}$ & & $3 / 0$ \\
\hline Myeloproliferative disorders & $5(26)$ & 2 type1; 1 type $2 \mathrm{~A} ; 1$ type $2 \mathrm{M} ; 1$ type 3 & & $0 / 0$ \\
\hline Multiple myeloma & $2(10)$ & 1 type $1 ; 1$ type $2 B$ & & $1 / 0$ \\
\hline Chronic lymphocytic leukemia & $1(5)$ & 1 type 1 & & $0 / 0$ \\
\hline Acute myeloid leukemia & $1(5)$ & 1 type 1 & & $0 / 0$ \\
\hline
\end{tabular}

Abbreviations: HCV, hepatitis C virus; HIV, human immunodeficiency virus; VWD, von Willebrand disease.

a94 cancers evaluable.

bOther cancers included skin $(n=6)$, thyroid $(n=4)$, meningioma $(n=4)$, thymus $(n=1)$, hypophysis $(n=1)$ and bone $(n=1)$.

'One skin cancer occurred in a VWD patient with HIV/HCV coinfection.

patients underwent 52 invasive and 72 surgical procedures, were treated with VWF/FVIII concentrates in 77 cases, with DDAVP alone in 24 cases and with DDAVP and VWF/FVIII concentrates in 7 cases. The median dose of VWF/FVIII concentrate and DDAVP administered was $45 \mathrm{IU} / \mathrm{kg}$ of VWF:RCo (range, 20-66 IU $/ \mathrm{kg}$ ) and $0.3 \mu \mathrm{g} / \mathrm{kg}$, respectively. The median duration of treatment was 2 days (range, 1-6 days) for invasive procedures and 9 days (range, 1-39 days) for surgical interventions. Hemorrhagic complications were observed only rarely ( $2 \%[1 / 52]$ of invasive procedures and $6 \%[4 / 72]$ of surgical interventions) and all but one (4/5, $80 \%$ ) occurred in VWD type 1 patients not receiving antihemorrhagic prophylaxis (median basal VWF:RCo levels: $27 \mathrm{IU} / \mathrm{dL}$, range, $24-30 \mathrm{IU} / \mathrm{dL}$ ). A total of $46 \%$ (37/81) and 31\% (22/71) of evaluable patients underwent chemotherapy and radiotherapy, respectively, with no antihemorrhagic prophylaxis. Hemorrhagic complications occurred in two patients (9\%) following radiotherapy. Eight of the 68 evaluable patients (12\%) developed thrombocytopenia (platelet count $<50 \times 10^{9} / \mathrm{L}$ ), which was in all cases associated with chemotherapy and/or radiotherapy. Finally, the recruiting physicians reported that the underlying inherited hemorrhagic disorder did not influence the choice or completion of the therapeutic protocol in any case nor had it resulted in a reduction of chemotherapy dosages.

\section{Discussion}

The existence of a correlation between cancer and hemostasis has been known for 150 years, ${ }^{19}$ with endogenous thrombin being identified as a major contributor to tumor implantation, seeding, and metastatization. ${ }^{20,21}$ Following observations from in vitro studies, ${ }^{22,23}$ in the last two decades investigators have analyzed this issue from the opposite side, that is, evaluating the antineoplastic effect of antiplatelet and anticoagulant agents. ${ }^{24-27}$ Besides these studies in pharmacologically anticoagulated patients, investigations have focused on naturally anticoagulated patients, that is, hemophiliacs. ${ }^{28-31}$ Accordingly, we previously conducted a retrospective survey among Italian HTCs collecting 127 cases of cancer in 122 hemophiliacs over a 30-year period (1980-2010).32 In this study, 83\% of patients were infected by HCV and $22 \%$ of them were also coinfected by HIV. A total of $43 \%$ of cancers were HCV-related, while $9 \%$ were HIV-related. Virus-related cancers were more frequent and nonvirus-related cancers less frequent in patients with severe hemophilia than in those with mild/moderate forms $(p=0.0004)$. Notably, considering nonvirus-related cancers, a low standardized mortality ratio (0.3) was found. Hemorrhagic complications occurred more frequently in patients undergoing chemotherapy $(14 \%)$ or radiotherapy (19\%). We therefore decided to do the same survey in Italian VWD patients. To our 
Table 3 Treatment characteristics of VWD cancer patients enrolled in the study

\begin{tabular}{|c|c|c|c|}
\hline Procedure & $\begin{array}{l}\text { Procedures/ } \\
\text { patients }\end{array}$ & $\begin{array}{l}\text { Antihemorrhagic } \\
\text { prophylaxis }\end{array}$ & $\begin{array}{l}\text { Hemorrhagic } \\
\text { complications (\%) }\end{array}$ \\
\hline \multirow[t]{4}{*}{ Invasive procedures } & \multirow[t]{4}{*}{$52 / 49$} & $28 \mathrm{VWF} / \mathrm{FVIII}$ & \multirow[t]{4}{*}{$1(2)$} \\
\hline & & 14 DDAVP & \\
\hline & & 4 VWF/FVIII + DDAVP & \\
\hline & & 6 none & \\
\hline \multirow[t]{4}{*}{ Surgical procedures } & \multirow[t]{4}{*}{$72 / 63$} & 49 VWF/FVIII & \multirow[t]{4}{*}{$4(6)$} \\
\hline & & 10 DDAVP & \\
\hline & & 3 VWF/FVIII + DDAVP & \\
\hline & & 10 none & \\
\hline Chemotherapy & $37 / 81$ & - & 0 \\
\hline Radiotherapy & $22 / 71$ & - & $2(9)$ \\
\hline
\end{tabular}

Abbreviations: DDAVP, desmopressin; HCV, hepatitis C virus; HIV, human immunodeficiency virus; VWF/FVIII, plasma-derived concentrates containing von Willebrand factor and factor VIII.

knowledge, this is the first study systematically investigating the occurrence of cancers in a cohort of VWD patients. This issue is however, in our opinion, potentially of great interest, also considering the implication of VWF in angiogenesis and tumor growth processes. Although we could not perform an epidemiological analysis of our data due to the limited number of cancer cases collected, some interesting information did emerge from this study. First of all, the lower number of VWD cancer patients infected by HCV and HIV infection (15\% and $2 \%$, respectively) as compared with hemophilia patients reported in our previous survey $^{32}$ reflects on the one hand the generally lesser clinical severity of VWD (with consequently less need for replacement therapy) and on the other hand the widespread use of DDAVP which prevented the exposure of a large number of VWD patients to nonvirally inactivated VWF/FVIII concentrates which were responsible for the transmission of blood-borne viruses during the 1970s and the first half of the 1980s. ${ }^{33}$ The results of our study further support the association between HCV and cancers: indeed, all cases of hepatocellular carcinoma occurred in HCV-infected VWD patients and approximately $30 \%$ of the cases of non-Hodgkin lymphoma were recorded in patients with concomitant HCV infection, in keeping with current literature data. ${ }^{34}$ The most striking finding of our study was, however, the association between VWD type and cancer. Indeed, we found an inversion of the ratio among the various VWD types, VWD type 2 being significantly more frequent in our cohort of cancer VWD patients than in the whole VWD population followed at the 18 HTCs participating in the study (33/92 [36\%] vs. 236/1465 [16\%]). This finding is particularly intriguing considering that, of the various different VWD types, VWD type 2 (especially subtype $2 \mathrm{~A}$ ) is that most frequently associated with angiodysplasia and thus could be involved in the abnormal angiogenesis at the basis of tumorigenesis. ${ }^{35,36}$ The hypothesis that cancer occurrence in VWD patients might be related to a qualitative rather than a quantitative VWF defect is further strengthened by the fact that the median basal VWF levels did not differ significantly between
VWD patients with or without a more aggressive malignancy (i.e., with metastasis) at presentation.

Notably, the fact that $80 \%$ of hemorrhagic complications associated with invasive or surgical procedures occurred in patients not receiving hemostatic treatment underlines the importance of prophylactic antihemorrhagic therapy, also in patients with milder VWD forms. Interestingly, although hemorrhagic complications occurred only rarely, 29\% (2/7) of such complications were observed in VWD cancer patients undergoing radiotherapy, probably reflecting a synergistic effect between treatment-related mucosal damage and the VWDassociated tendency to mucosal bleeding. This finding suggests that particular caution should be taken and antihemorrhagic prophylaxis should be considered before starting radiotherapy in such patients at increased risk of mucosal bleeding. Finally, the finding that none of the cases of cancer metastasis at diagnosis occurred in patients with VWD type 3 is potentially interesting but needs to be confirmed by larger studies.

In conclusion, the data collected by this survey document that a substantial number of cancers are recorded among VWD patients and that they can usually be managed safely by physicians operating at HTCs through a multidisciplinary approach. Further experimental and clinical studies are needed to assess whether or not VWD predisposes to cancer.

\section{References}

1 Ruggeri ZM. Structure of von Willebrand factor and its function in platelet adhesion and thrombus formation. Best Pract Res Clin Haematol 2001;14(2):257-279

2 Franchini M, Lippi G. The role of von Willebrand factor in hemorrhagic and thrombotic disorders. Crit Rev Clin Lab Sci 2007;44(2): 115-149

3 Castaman G, Federici AB, Rodeghiero F, Mannucci PM. Von Willebrand's disease in the year 2003: towards the complete 
identification of gene defects for correct diagnosis and treatment. Haematologica 2003;88(1):94-108

4 Franchini M, Frattini F, Crestani S, Bonfanti C, Lippi G. von Willebrand factor and cancer: a renewed interest. Thromb Res 2013;131(4):290-292

5 Starke RD, Ferraro F, Paschalaki KE, et al. Endothelial von Willebrand factor regulates angiogenesis. Blood 2011;117(3): 1071-1080

6 Terraube V, Pendu R, Baruch D, et al. Increased metastatic potential of tumor cells in von Willebrand factor-deficient mice. J Thromb Haemost 2006;4(3):519-526

7 Terraube V, Marx I, Denis CV. Role of von Willebrand factor in tumor metastasis. Thromb Res 2007;120(Suppl 2):S64-S70

8 Hatzipantelis ES, Athanassiou-Metaxa M, Gombakis N, et al. Thrombomodulin and von Willebrand factor: relation to endothelial dysfunction and disease outcome in children with acute lymphoblastic leukemia. Acta Haematol 2011;125(3):130-135

9 Schellerer VS, Mueller-Bergh L, Merkel S, et al. The clinical value of von Willebrand factor in colorectal carcinomas. Am J Transl Res 2011;3(5):445-453

10 Wang WS, Lin JK, Lin TC, et al. Plasma von Willebrand factor level as a prognostic indicator of patients with metastatic colorectal carcinoma. World J Gastroenterol 2005;11(14):2166-2170

11 Zietek Z, Iwan-Zietek I, Paczulski R, Kotschy M, Wolski Z. von Willebrand factor antigen in blood plasma of patients with urinary bladder carcinoma. Thromb Res 1996;83(5):399-402

12 Gadducci A, Baicchi U, Marrai R, Del Bravo B, Fosella PV, Facchini V. Pretreatment plasma levels of fibrinopeptide-A (FPA), D-dimer (DD), and von Willebrand factor (vWF) in patients with ovarian carcinoma. Gynecol Oncol 1994;53(3):352-356

13 Kim SM, Myoung H, Choung PH, Kim MJ, Lee SK, Lee JH. Metastatic leiomyosarcoma in the oral cavity: case report with protein expression profiles. J Craniomaxillofac Surg 2009;37(8):454-460

14 Jiang WG, Watkins G, Douglas-Jones A, Holmgren L, Mansel RE. Angiomotin and angiomotin like proteins, their expression and correlation with angiogenesis and clinical outcome in human breast cancer. BMC Cancer 2006;6:16

15 Josefsson A, Wikström P, Granfors T, et al. Tumor size, vascular density and proliferation as prognostic markers in GS 6 and GS 7 prostate tumors in patients with long follow-up and non-curative treatment. Eur Urol 2005;48(4):577-583

16 Gallego L, Junquera L. Association von Willebrand's disease and nevoid basal cell carcinoma syndrome (Gorlin syndrome). Haemophilia 2008;14(4):835-837

17 Bercaw JL, Sanchez J, Byrd RH, Bhattacharjee MB, Dietrich JE. Sex cord tumor with annular tubules in a young adolescent with Von Willebrand's disease. J Pediatr Adolesc Gynecol 2010;23(3): e111-e114

18 Boldorini R, Allegrini S, Tognon M, et al. Merkel cell carcinoma arising in inguinal lymph node in a patient with von Willebrand disease after multiple blood transfusions. J Clin Virol 2014;60(1): 73-75
19 Trousseau A. Phlegmasia alba dolens. In: Trousseau A, ed. Clinique medicinale de l'Hotel-Dieu de Paris. Paris, France: JB Bailliere et fils; 1865:645-712

20 Hu L, Lee M, Campbell W, Perez-Soler R, Karpatkin S. Role of endogenous thrombin in tumor implantation, seeding, and spontaneous metastasis. Blood 2004;104(9):2746-2751

21 Franchini M, Montagnana M, Targher G, Manzato F, Lippi G. Pathogenesis, clinical and laboratory aspects of thrombosis in cancer. J Thromb Thrombolysis 2007;24(1):29-38

22 Langer F, Amirkhosravi A, Ingersoll SB, et al. Experimental metastasis and primary tumor growth in mice with hemophilia $A$. J Thromb Haemost 2006;4(5):1056-1062

23 Brüggemann LW, Versteeg HH, Niers TM, Reitsma PH, Spek CA Experimental melanoma metastasis in lungs of mice with congenital coagulation disorders. J Cell Mol Med 2008;12(6B):2622-2627

24 Franchini M, Mannucci PM. Thrombin and cancer: from molecular basis to therapeutic implications. Semin Thromb Hemost 2012; 38(1):95-101

25 Franchini M, Mannucci PM. Low-molecular-weight heparins and cancer: Focus on antitumoral effect. Ann Med 2015;47(2):116-121

26 Cunningham MS, Preston RJS, O'Donnell JS. Does antithrombotic therapy improve survival in cancer patients? Blood Rev 2009; 23(3):129-135

27 Sanford D, Naidu A, Alizadeh N, Lazo-Langner A. The effect of low molecular weight heparin on survival in cancer patients: an updated systematic review and meta-analysis of randomized trials. J Thromb Haemost 2014;12(7):1076-1085

28 Franchini M, Lippi G, Montagnana M, et al. Hemophilia and cancer: a new challenge for hemophilia centers. Cancer Treat Rev 2009; 35(4):374-377

29 Franchini M. Haemophilia and cancer: a personal perspective. Blood Transfus 2013;11(1):26-31

30 Dunn AL. Malignancy in patients with haemophilia: a review of the literature. Haemophilia 2010;16(3):427-436

31 Miesbach W, Seifried E. Does haemophilia influence cancerrelated mortality in HIV-negative patients? Haemophilia 2011; 17(1):55-60

32 Tagliaferri A, Di Perna C, Santoro C, et al; Italian Association of Hemophilia Centers. Cancers in patients with hemophilia: a retrospective study from the Italian Association of Hemophilia Centers. J Thromb Haemost 2012;10(1):90-95

33 Mannucci PM. Desmopressin (DDAVP) in the treatment of bleeding disorders: the first 20 years. Blood 1997;90(7):2515-2521

34 Marcucci F, Mele A. Hepatitis viruses and non-Hodgkin lymphoma: epidemiology, mechanisms of tumorigenesis, and therapeutic opportunities. Blood 2011;117(6):1792-1798

35 Franchini M, Mannucci PM. Gastrointestinal angiodysplasia and bleeding in von Willebrand disease. Thromb Haemost 2014; 112(3):427-431

36 Federici AB, Bucciarelli P, Castaman G, et al. The bleeding score predicts clinical outcomes and replacement therapy in adults with von Willebrand disease. Blood 2014;123(26):4037-4044 


\section{Author Query Form (STH/02235)}

Special Instructions: Author please write responses to queries directly on proofs and then return back.

Q1: Percentage values are absent in the table columns. Please check 